\title{
Women's Road Movies and Affirmative Wandering: Messidor
}

\begin{abstract}
For the voyageuse to exist as nomadic subject, a different idea of voyage and different housing of gender is to be sought: travel that is not a conquest, dwelling that is not domination. A place where nostalgia is replaced by transito-a mobile map.
\end{abstract}

(Giuliana Bruno 2002, 86)

Giuliana Bruno's words resonate with the idea behind this book that both subjects and places are in continual transformation. Whether traveling through or dwelling in a place, mobility and habitation are about constant change; power relations, subjects, and places are never fixed. While patriarchal structures negatively affect women's movement and travel, affirmative forces arise from these forms of oppression, which appear particularly clearly when analysing women in the road movie genre. As we will discover through this chapter, this analysis suggests that women's mobility cannot and should not be compared to men's. In critiques of road movies involving women protagonists, the mobility of the characters is often seen as a non-mobility and a lack of achievement when compared to men's mobility in the traditional road movie. The bitterness that arises from these films often arises from the many economic and social obstacles women encounter on the road, as well as from a much-too-common dependency on men to achieve mobility, such as in 
Wanda (Barbara Loden 2006 [1970]), Germany, Pale Mother (Helma Sanders-Brahms 2008 [1980]), Mortelle randonnée (Claude Miller 1983), Sans toit ni loi (Agnès Varda 1985), Thelma and Louise (Ridley Scott 2002 [1991]), Butterfly Kiss (Michael Winterbottom 1995), Monster (Patty Jenkins 2003), Morvern Callar (Lynne Ramsay 2003), In July (Fatih Akin 2004), Marseille (Angela Schanelec 2004), Transylvania (Tony Gatlif 2006), My Blueberry Nights (Wong Kar-Wai 2007), Yella (Christian Petzold 2007), Wendy and Lucy (Kelly Reichardt 2008), and American Honey (Andrea Arnold 2016). Rather than placing women's (non-)achievement against men's, this chapter will use an affirmative lens to explore how women's wilful habitation of space manifests on screen in the road movie Messidor (Alain Tanner 1995 [1979]), a film made in continuation of the feminist movements of the 1970s.

As many film scholars have noted, the road movie is generally dominated by male protagonists, while examples of 'women road movies' are scarce (Cohan and Hark 1997; Corrigan 1992; Eyerman and Löfgren 1995; Gott and Schilt 2013; Laderman 2002; Mazierska and Rascaroli 2006; Mills 2006; Orgeron 2008; Pérez 2011). The road movie is traditionally recognised by a male protagonist who undertakes a self-reflective quest away from home, with the home often representing a conservative lifestyle that he hopes to escape. Timothy Corrigan describes road movies in the following manner:

the heroes of these travelogues embark on a learning experience that becomes most historically determined in bildungsroman tradition: the familiar is left behind or transformed through the protagonist's movement through space and time, and the confrontations that he encounters generally lead, in most cases, to a wiser individual and often a more stable spiritual or social state. $(1992,144)$

Through physical mobility, the protagonist hopes to find the freedom that being on the road promises and, if possible, even achieve social mobility (Eyerman and Löfgren 1995, 56-57). The familiar, or 'home', appears in opposition to travel. In The Road Movie Book, editors Steve Cohan and Ina Rae Hark write that 'the road movie promotes a male escapist fantasy linking masculinity to technology and defining the road as a space that is at once resistant while ultimately contained by the responsibility of domesticity: home life, marriage, employment' (1997, 3). Home becomes at once a space of conventions and one of lost intimacy that the protagonist 
hopes to regain on the road. The road thus becomes an alternative to 'home', where the main character searches for a more 'authentic' space of intimate relations.

In contemporary cinema, and in road movies in particular, the notion of home often signifies a familiar domestic space associated with women and in opposition to mobility and the 'masculine' (see Blum-Reid 2016; Bruno 2002; De Lauretis 1984; Fullwood 2015; Frederick and Hyde 1993; Mazierska and Rascaroli 2006; Robertson 1997; Rollet 2003; Royer 2011). Giuliana Bruno describes how the notion of home, of one's origin, of domus - domesticity, domestication-in male narratives of travel 'continues to be confused and gendered feminine' $(2002,86)$. As such, home has acquired a meaning of 'the womb from which one originates and to which one wishes to return' and has become 'the very site of the production of sexual difference' (Bruno 2002, 86). In travel narratives, returning and 'repossessing' home often emerge as repossessing the female subject or 're-housing gender'. Instead, Bruno argues for rewriting home as a sphere of the possible, emphasising it as a space that is always in transito, in writing, constantly made and remade through time and social relations.

Road movies with women protagonists are often considered to be a rewriting of the male genre, in the same way that European road movies 'seem a reaction to, or reformulation of, the American genre' (Laderman 2002, 247). Accordingly, scholars have relegated both European and 'women's road movies' to the last chapter of their works (see Cohan and Hark 1997; Corrigan 1992; Eyerman and Löfgren 1995; Laderman 2002; Orgeron 2008; Pérez 2011). With the exception of the recent collection of essays Open Roads, Closed Borders: The Contemporary French-Language Road Movie, edited by Gott and Schilt (2013), women's road movies are treated separately from other road movies and are typically cast as an alternative to the male genre. If both the European and women's road movies appear at the margins of the generic definition of the road movie, onscreen 'appropriations' of the genre by women characters have not been as successful as the European ones. As mentioned, women have to overcome many obstacles before even starting their journey, including a lack of a means of mobility (transport, economic independence) and limited agency in the public sphere when compared to their male counterparts. Women's journeys also tend to end in more troublesome predicaments than the journeys men undertake on screen. A handful of scholars have looked for fruitful feminist models for mobility throughout the road movie genre 
(see Blum-Reid 2016; Mazierska and Rascaroli 2006; Rollet 2003; Royer 2011; Tarr and Rollet 2001). To give one example: In their analysis of the film Morvern Callar (Lynne Ramsay 2003), Ewa Mazierska and Laura Rascaroli suggest that 'the best way of travelling is not travelling', as the protagonist only finds satisfaction in relative immobility $(2006,197)$-in other words, it is difficult for women to inhabit and belong to 'public' places. Mazierska and Rascaroli rightly conclude their chapter on women's mobility in Crossing New Europe: Postmodern Travel and the European Road Movie by underlining the many social and economic conditions that women need to fulfil, as opposed to men, before they can even begin their travels or become (successful) travellers $(2006,198)$. The above studies have noted how women tend to move in a less expansive manner as male protagonists; instead, women seem to be spatially limited by gender roles and expectations: first, to get out of the house and then second, onto the road itself. They often wander aimlessly, disempowered or dependent on other (male) characters to achieve mobility. I share the conclusions of a number of these scholars that women's mobility might not be identifiable through the male narratives of travel (see Bruno 2002; Frederick and Hyde 1993; Mazierska and Rascaroli 2006; Pratt 2012; Uteng and Cresswell 2008). Significantly, few of these scholars provide alternative models, with a recent exception in the work of Kate Ince (2017), who turns to phenomenology to consider women's mobility through body movements.

By offering a detailed examination of women's bodily relations to space, this chapter aims to put into practice what the previous chapter suggested theoretically. Whereas the gendered dimension of women's bodies conditions their access to and control over their mobility and habitation of space, a micro-analysis of space and bodies on screen allows us to see how Messidor produces affirmative forms. The film aesthetically transgresses and transforms the traditional road movie genre and its representation of space as immutably gendered and inflected by established (that is, seemingly fixed) power-geometries. While Tanner's film exemplifies the obstacles to women's mobility, it also critiques the concept of mobility itself, by which women and men are opposed in terms of stasis and transformation (see Uteng and Cresswell 2008). Rather than emerging through extensive travel, the affirmative forces of Messidor take shape at a microlevel. It is through the characters' affective relations to space that the film aesthetically untangles mobility from masculinity, power, and the possession of home. 
As the opening credits unroll, a series of forward and lateral tracking shots filmed from a helicopter establishes the setting for Messidor. Travelling across countryside and peripheral highways, and ending its course in the mountains, the camera sets the landscapes for the protagonists' journey. The sudden changes of directions of the filming, with the camera filming ahead or completely tilted towards the ground, create a disjointed scene. The lateral tracking shots from right to left, opposite to the Western direction of reading, evoke the desolation and fatalism contained in Schubert's song 'Gute Nacht', part of his 'Winterreise', that plays during the scene. In the music and the cinematography of this sequence, and in the film as a whole, Alain Tanner alternates moments of hope and hopelessness. The music's lyrics and variations between major and minor tones, and the contrast between its title 'Winterreise' (meaning 'winter travel') and the film's title Messidor (referring to the first summer month in the old French Republican calendar), foreground the uneven adventures of the protagonists, Jeanne and Marie. If the path of Jeanne and Marie is 'covered in snow'-or obstacles-like in the beginning of Schubert's song ('Der Weg gehüllt in Schnee'), they will still 'roam on the road rather than linger in the master's house' ('Lass irre Hunde heulen; Vor Ihres Herren Haus!; Die Liebe liebt das Wandern'): both Jeanne and Marie were living with a man who had some power over the house before going on their journey. Reading Messidor through an affirmative lens brings attention to the film's critical perspective upon women's difficulties in travelling, as well as to the aesthetic shaping of the protagonists' wilful habitation of space.

The transgressive intentions of Messidor are evident from the beginning of the film, when Jeanne rebels against a misogynist man who picks her and Marie up. Marie, another woman hitchhiker. Marie soon abandons her plan to return home to her mother and unpalatable stepfather, and joins Jeanne to wander around the countryside. As they travel together around Switzerland without aim or money, Jeanne and Marie have to rely on others, predominantly on men, to provide them with transport, food, and accommodation. After resisting a sexual assault, they steal a policeman's gun out of his glove box and as a result are pursued as 'criminals'. Their portrayal as dangerous women on national television limits their ability to move around freely. At the conclusion of the film, they mistakenly kill a man in a café and are arrested.

Comparing Messidor briefly with another European road movie produced three years prior, Kings of the Road (Wim Wenders 1976), involving 
two male strangers bonding on the road, pinpoints the extra difficulties Jeanne and Marie encounter on their journey because of their gender. Three main differences emerge. First, in Kings of the Road, the male protagonists, Bruno and Robert, have a vehicle (a truck) and economic means to travel, while Jeanne and Marie lack transport and money, and thus are restricted and dependent (mostly on men) for access to mobility (generally understood as long travel in road movies). Whereas Bruno and Robert's ownership of a vehicle allows them unproblematic access to the social spaces ${ }^{1}$ which is also granted by their bodies gendered as masculine, Jeanne and Marie's lack of a car positions them in a vulnerable situation, also created by a patriarchal society which portrays their female bodies as problematic. Second, while Bruno and Robert's truck provides them with a space of intimacy, a space to bond and express their desires, Jeanne and Marie are vulnerable and in danger because of the absence of any kind of dwelling space. Unlike Bruno and Robert, Jeanne and Marie are unable to return to the domestic space and repossess it, nor are they able to find a 'home' on the road, it being a constraining space for women. Third, through their bonding and mobility, the two men appraise the road as a space that they can fully inhabit, and experience a journey of self-transformation. In contrast, Jeanne and Marie lose their independence on the road as their bonding becomes necessary for their survival. They seem trapped in an image of themselves as dangerous women, threatening to a patriarchy that strives to maintain their wilful bodies in a hierarchical, dichotomous situation as gendered bodies.

While gendered identities and expectations determine Jeanne and Marie's journey and fate, their wilfulness brings up affirmative forms on screen. Jeanne and Marie's lack of money, means of transport, and inadequacy in social spaces foreground the way in which space is gendered, preventing them from dwelling and moving with ease. From the beginning of the film, Tanner makes clear that the road does not offer the same 'freedom' to women as it does to men. On their journey, Jeanne and Marie meet numerous bourgeois men who display a paternalistic attitude towards them, advising them on life, economy, and travel. However, Jeanne and Marie are portrayed as disobedient and wilful to fully inhabit space, and as better educated than most of the male characters they meet on the road, whose actions and discourses appear petty, reactionary, and absurd. By performing a micro-analysis of how the two women inhabit the three contested spaces of the road movie genre, the car, the road and home, it becomes clear that the wilfulness of the protagonists take affirmative forms on screen, which need to be read for and made visible. 
While the first scene uniting Jeanne and Marie narratively sets the negative tone for the entire film, emphasising the difficulties the two women will encounter on the road, the scene also takes affirmative forms that a microanalysis can reveal. The first man to give them a ride is a misogynist neoliberal man who complains about 'working his ass off' for other people to study and is especially critical of the fact that 'all girls go to university now'. Jeanne, herself a student, responds to this critique, answering in a manner far superior to that of the driver, her eloquent intervention resulting in the women being left on the side of the road. The tight close-up framing of the misogynist man from a slight low angle (see Fig. 2.1) characterises him as an overtly ridiculous, pedantic voice. The shallow focus of the filming of the man's head, blurring the road in the background, displaces his voice, making its discourse look out of time and space, somewhat universally (or widely) accepted, though harmful. The dissonant violin chords that resonate during the scene, and are then heard again repeatedly during the film, help to create a hostile atmosphere, suggesting that the road is dangerous for the two women. The camera, however, frames Jeanne and Marie together in the backseat in a medium shot that makes the passing road visible in the back window (see Fig. 2.2). Their visual situatedness in time and

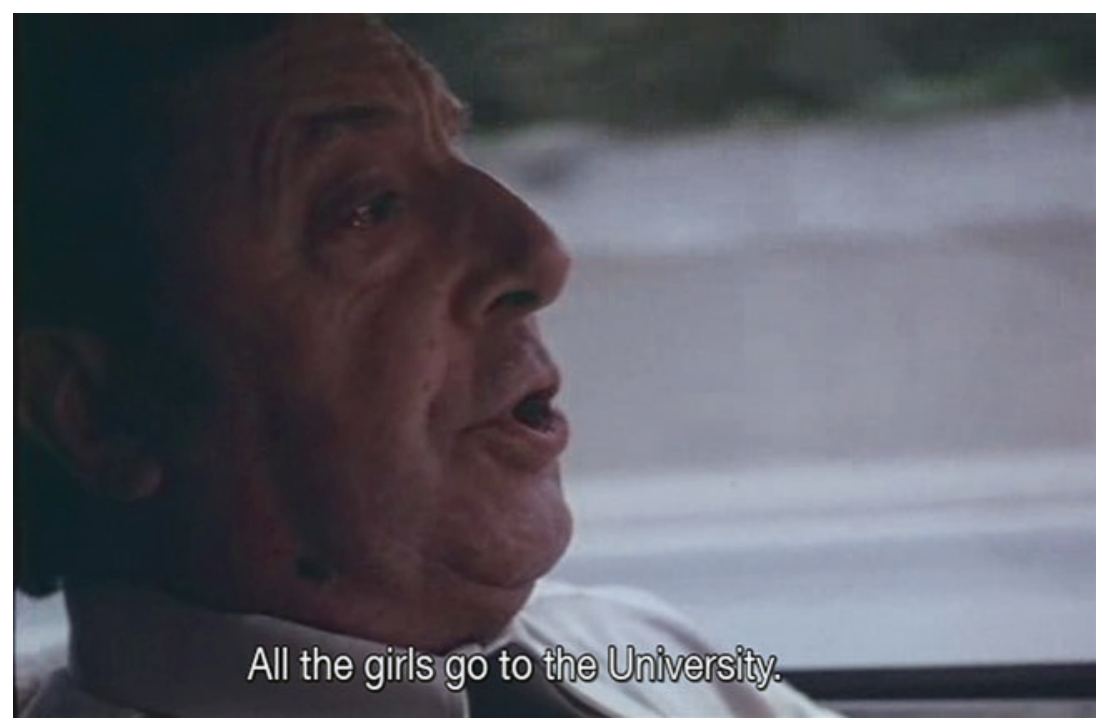

Fig. 2.1 Messidor: First misogynist driver 


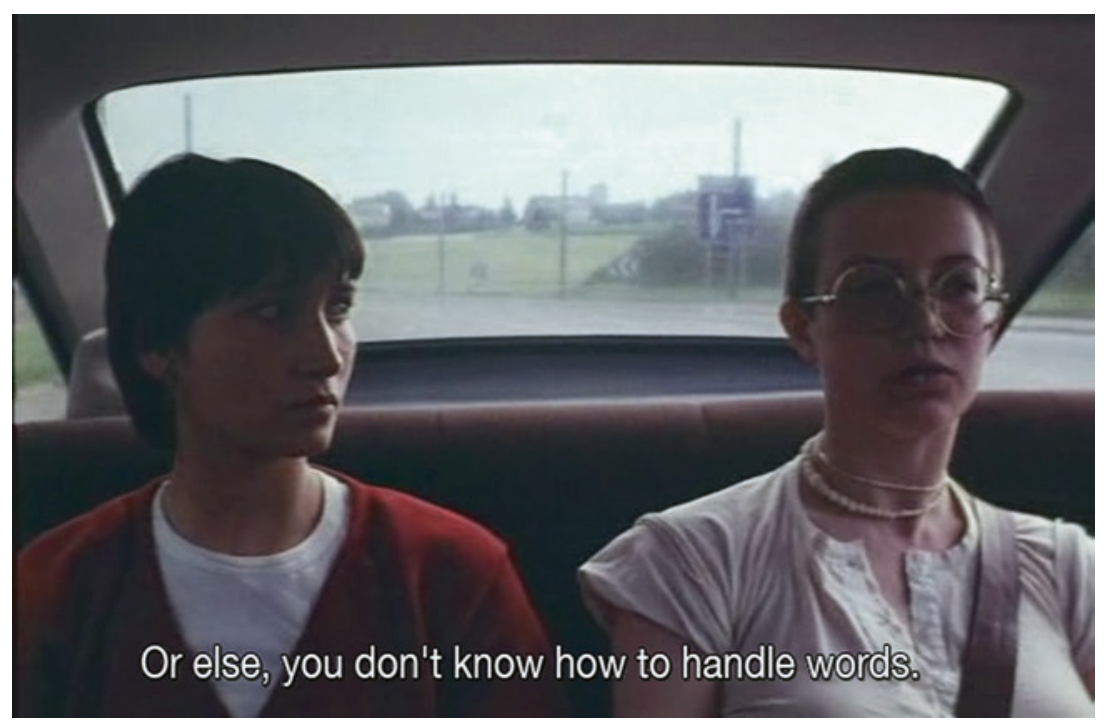

Fig. 2.2 Messidor: Jeanne answers back

space, and the eloquence of Jeanne's response compared to the man's simplistic speech, place them in an affirmative situation. Whereas the film diegetically points to the pessimistic conclusion that subversion of the patriarchal and capitalist Swiss society as a whole is insurmountable, wilful affects are aesthetically visible from the start. Rather than on encounters and selftransformation, the focus of this unconventional road movie is on the process, albeit a struggle doomed to fail, of inhabiting and moving through space as unaccommodated bodies.

As opposed to traditional road movies, which involve the mobility of characters in their car or another personal vehicle, Messidor shows how the absence of a car implies an absence of a space of intimacy. The protagonists' lack of economic resources and means of transport of their own leads to their alienation from society. Cars in fact figure as impersonal objects, metaphors for the capitalist patriarchal society as a whole, which is unaccommodating to characters such as Jeanne and Marie. When the voices of the male drivers are heard or part of their faces are shown, it is to emphasise their paternalistic, at times racist, speech as obstacles to the women's intention of mobility. As if seeing from another passenger's perspective, the camera often films the road ahead rather than the driver, as would be expected 
in a road movie. Such a disembodiment of the male characters, contrasting with the deeply embodied Jeanne and Marie, shows how little the negativity emanating from these characters affects the wilfulness of the protagonists to travel. Similarly, as two men assault Jeanne, the camera remains distant and fixed during the whole scene and only changes to a closer shot when Marie grabs a rock to knock out the attackers. Even if they lack a vehicle of transport and protection, Jeanne and Marie appear as empowered, wilful women instead of passive victims, who put their bodies in the way of patriarchy and gender expectations.

An analysis of Messidor within the framework of the road movie genre would only lead to the negative statements formulated earlier: of the impossibility of the women to become flâneuses because of their constant sexualisation through the male gazes they encounter. In contrast with the traditional road movie involving men travellers, Messidor does not focus on self-transformation or finding the meaning of home on the road, but instead on the wilfulness to become mobile and on the institutionalised sexism that limits Jeanne and Marie's full habitation of space. Jeanne and Marie's view of travel resonates with Frederick and Hyde's observation of women's travel in travel-writing literature:

Movement becomes a way to combat a feeling of homelessness that has nothing to do with the physical site of home. (xxi) ... Whatever the reasons for embarking on a journey, women travellers both accept and embrace risk. ... no danger means no freedom. ... when the journeyer exults in danger and celebrates her survival, she is glorying in the freedom to be in danger. (1993, xxii)

As Jeanne and Marie also affirm 'if you don't take risks, you go nowhere' ('si on ne risque rien, on a rien'), the risks they take by venturing into a space dominated by men become the risks necessary to combat their feeling of homelessness. The protagonists find affirmation through the recognition of the 'limitations to their freedom' and their liberation from the 'burden of negativity' (in Braidotti's words).

Wilful affects translate as persistence in moving, incessant movement on screen. Jeanne and Marie mock their own representation as dangerous women on television and the injunctions that the road is dangerous for women 'alone' (read: without men), similarly to the women protagonists of later films such as Thelma and Louise (Ridley Scott, 1991), Butterfly Kiss (Michael Winterbottom, 1995), Monster (Patty Jenkins, 2003), and 
Frozen River (Coutney Hunt, 2008). To keep moving is their weapon against the unjust power-geometries that define the road and other 'public' spaces, to go on a journey whose only goal is not to go bome-a journey that began with Jeanne's desire to leave her apartment and Marie's refusal to go back to her mother's house. While the car appears as a masculine space par excellence where they only are passengers-no woman is shown driving in the whole film-houses and interior spaces such as cafés and restaurants epitomise the bourgeoisie that Jeanne and Marie's journey protests against. Jeanne expresses how she hates the 'cute little houses' that they see in the small town of Aarberg. The dialogue emphasises how home is a space of domesticity and conventions, as opposed to the playful aspect of the road and the 'freedom' that movement brings. Despite their lack of economic resources, the women agree to continue travelling, with Jeanne stating, 'either we act conventionally and go home like everyone else, or we can play a game... we go on... until we find out. I'm not sure what, but that's beside the point'. As in Head-On, as the last chapter will explore, the possibility of transforming the power-geometries of space takes shape in Messidor through its aesthetic forming of space and subjects as fluid, rather than in its diegesis. Just as in Vendredi soir or in Wadjda, 'finding out' may mean finding another kind of home, one that is in transit and one that they inhabit affectively.

The Swiss landscape becomes their home, a space of both liberation and boredom. The film leaves behind a messy cartography, as Jeanne and Marie cross linguistic boundaries and go around in circles, up the mountain and back down again, to the city and back to the countryside, as it becomes increasingly clear that the road is the protagonists' real home. As Jeanne and Marie become increasingly alienated from social spaces-dominated by middle-aged, middle-class men-the mountains become their new dwelling. It is where they take refuge, their safe space, albeit one that is hostile to habitation because of the lack of food. The almost constant sunny weather in Messidor (also expressed through the title) provides the road journey with an optimism that the general sociality of its space lacks. When the two women first head to the mountains, with the goal to 'go up and even further, to the point of no return', they are shown in an extremely long shot in high angle as they walk up the mountain. They are seen as tiny bodies only made visible by their movement through the monotonous gray rock and small patches of snow; they inhabit a space that absorbs them, an environment into which they visually merge (see Fig. 2.3). The silence, length, and fixity of the take, along with the faint, occasional bird song, constitute a peaceful atmosphere. After the two women have climbed the 


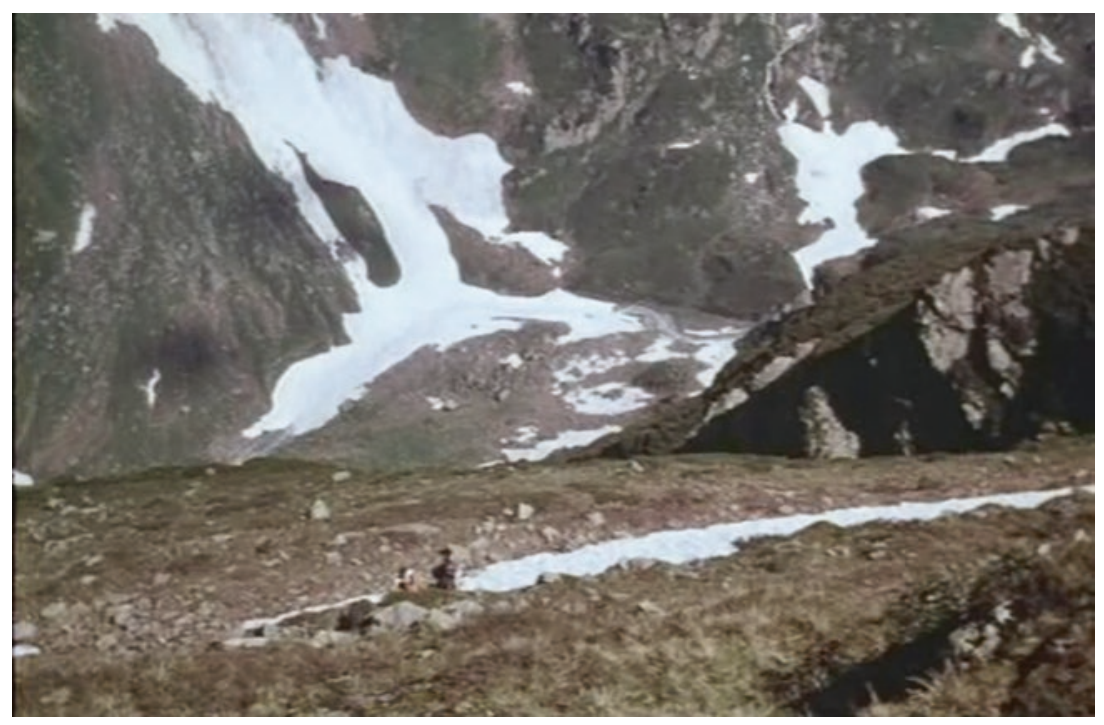

Fig. 2.3 Messidor: Long shot of Jeanne and Marie walking up the mountain

ridge and emerge onto a grassy plateau, fixed medium shots situate them in an environment that they fully inhabit. Jeanne opens her arms in a V-shape towards the sky (see Fig. 2.4), and in a seamless movement slowly lets herself slide onto the rock behind her, adapting her body to its shape. Jeanne's silent exclamation, in spite of her open mouth, echoes the silence of the environment. Her standing body reiterates the mountain lines, instead of disturbing the cinematic space.

Similarly, the camera, Marie's body and the rock behind her form a perfect line. The visual and aural representation of Jeanne and Marie in the mountains give affirmative shape to their habitation of space. These moments of affirmative aesthetics indicate the optimism that emerges from the film-Jeanne's cheerful body is also featured on the cover of the released video-despite the abundance of obstacles that the two women confront in the urban space. Rather than offering the 'possibilities of resistance' that Elizabeth Wilson identified for the flâneuse in the modern city $(1991,8)$, the city in Messidor is hostile. The film instead adopts the trope of finding oneself in nature, in the great outdoors - a trope that may appear somehow cliché in its usual association with femininity, but that in Tanner's film connotes rebellion against capitalism (a foundation of 1970s social movements). 


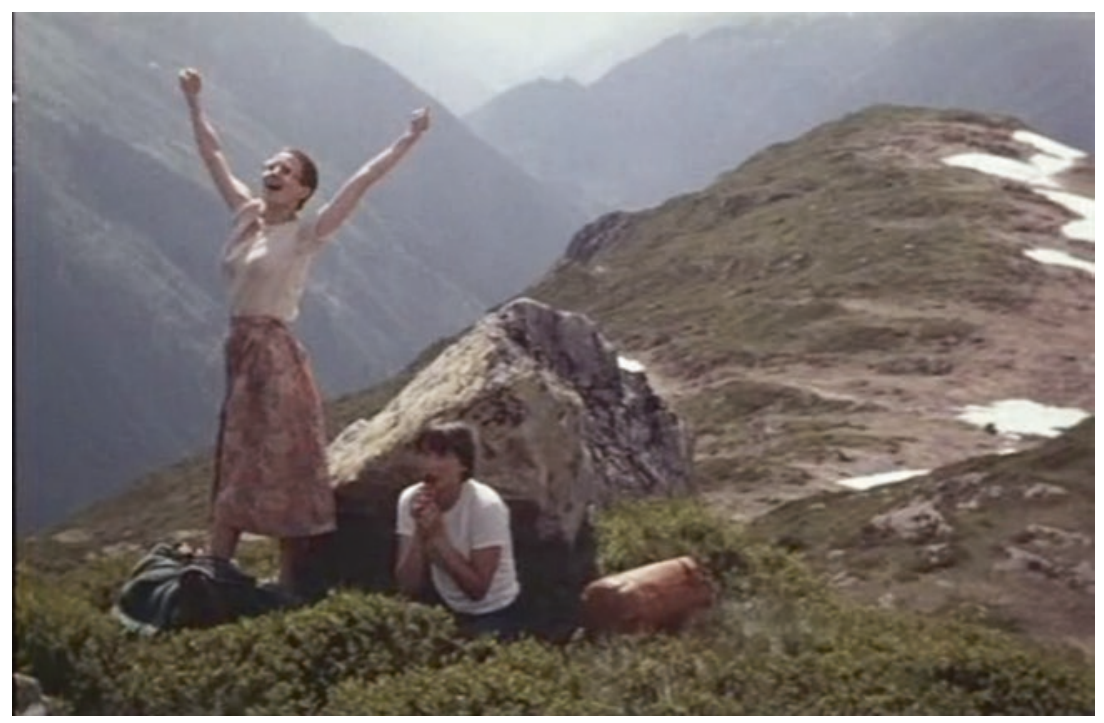

Fig. 2.4 Messidor: Jeanne and Marie seamlessly inhabit their spatial environment

Fig. 2.3 Messidor: Long shot of Jeanne and Marie walking up the mountainFig. 2.4 Messidor: Jeanne and Marie seamlessly inhabit their spatial environmentWhile a narrative reading of Messidor may hinder its optimism by setting excessive attention on the women's failure to travel expansively and become flâneuses as men are able, the micro-analysis of cinematic spaces unveils how the film displaces the centre rather than marginalising its protagonists from the urban space. If cities and cars appear as the shelter of capitalism and the bourgeoisie, the mountains and lakesides become the homeland of the rebellious youth, the youth at the centre of the May 68 movement and the youth that appear as the protagonist of Tanner's film Jonas qui aura 25 ans en l'an 2000 (Tanner 1992 [1976]). The only overtly joyful music in Messidor, an oriental score during which Jeanne and Marie dance in a moment of affirmation, symptomatically resonates on the border of a lake in the mountains. As in the next scene, when Jeanne and Marie decide not to cross the Swiss border into Italy after being publicly portrayed as criminals, the deep silence, majestic landscape, and high surrounding mountains give form to an immense space that is in constant transformation, both accommodating, giving rise to affirmative affects, and persistently unwelcoming, the sign of the loneliness of resistance to the status 


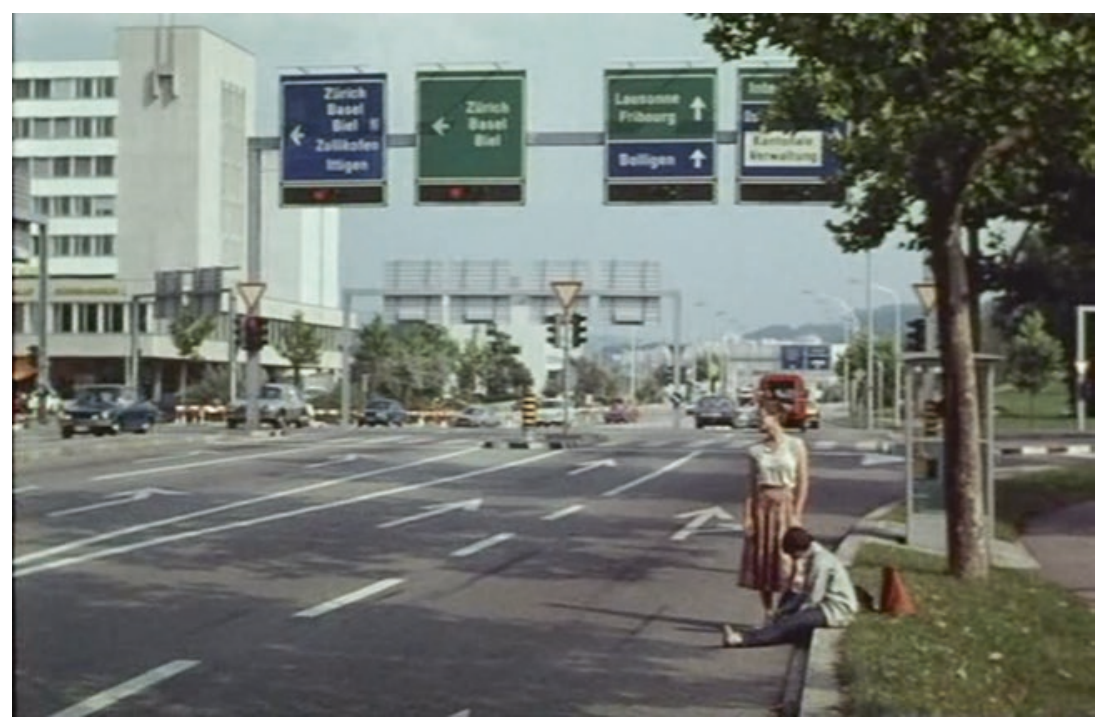

Fig. 2.5 Messidor: The road forms a social border difficult to cross for Jeanne and Marie

quo. The sudden heavy sound of traffic interrupts the silence of the mountains and situates the two hitchhiking women on the side of a busy road (see Fig. 2.5). The dissonant score in a minor key and the long take of the two small bodies framed in a long shot immobile on the side of the road-in opposition to the movement of the cars in the centre of the frame-produce a sense of entrapment, an entrapment into a sexist system, which the urban space embodies and from which it is difficult to escape. Whereas the road forms a visual border on screen, maintaining the women in stasis and on the margins of the public sphere, the mountains become their home on the road, a 'room for themselves'. As we will see in the following chapters, affirmation of wilful women often coincides with establishing and inhabiting one's own space, which manifest both diegetically and aesthetically.

Movement figures as a remedy for the homelessness of the protagonists. The protagonists' persistence in the face of adversity-their constant sexual commodification and paternalistic belittling-takes shape as they take the road and keep moving without stopping. The movement of the camera and of the bodies on screen give form both to the duration and the disobedience involved in their resistance. The slow rhythm of the film, its 
lack of frequent action, and numerous ellipses emphasise the long-lasting persistence of the protagonists against the power-geometries they have to face. Scenes often start in medias res (such as in Homer's The Odyssey): in the middle of conversations, with a response to an unheard question, or by framing a landscape in a fixed shot that the moving bodies of the protagonists interrupt. The lack of chronology and cartography of the women's journey creates a sense of affective duration, not limited by time and space but expandable across times and spaces through how one is affected and affects others. The wilful affects of the protagonists are demonstrated on screen as disobedience, going against the flow, and occupying space. When Jeanne and Marie walk on the side of the road, the camera films them in tracking shots from right to left, walking against the traffic that flows in a conventionally forward direction from left to right on the screen. As they philosophically reflect on their own movement in empty space... [becoming] interesting', their paused bodies and their voices take the foreground while the passing cars and the sounds of traffic are relegated to the background (see Fig. 2.6). Their bodies taking space on screen give form to wilful affects, as a refusal to go with the flow of the patriarchal capitalist system. The aesthetic choices of this scene show how their paused

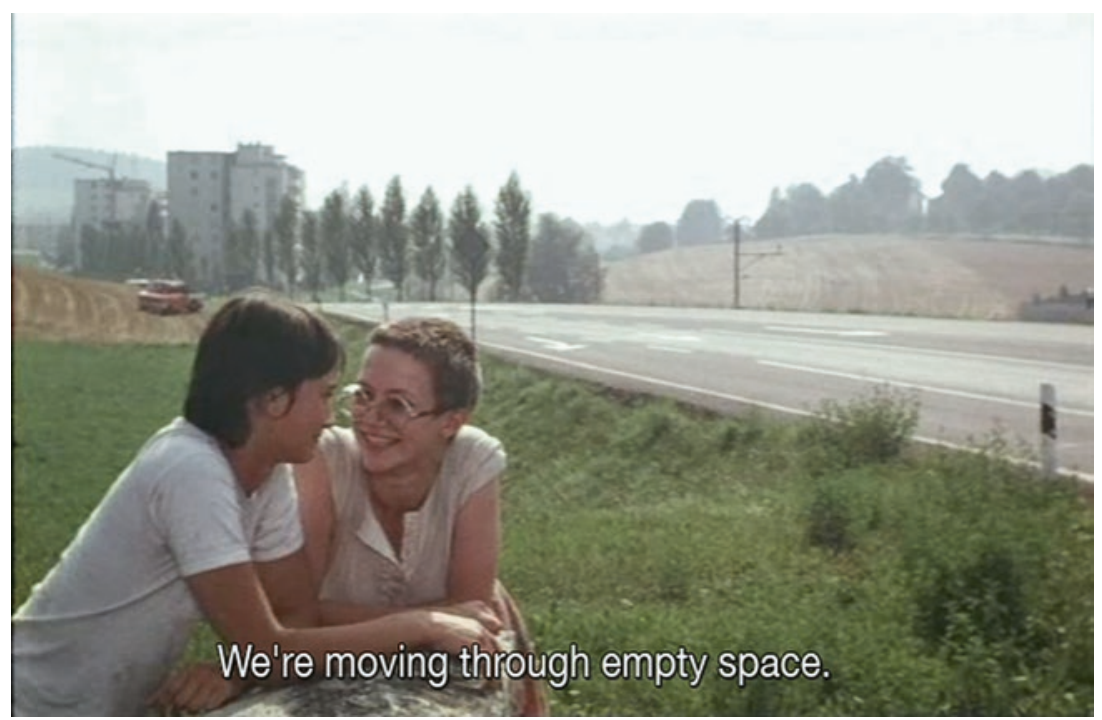

Fig. 2.6 Messidor: 'We're moving through empty space' 
reflection empowers them and affirmatively turns them into the Greek idiotes in opposition to the pedantic rhetoric of the men they cross paths with (see Chris Ingraham's book Gestures of Concern (2020) on the empowered concern of idiotes). If, as Ingraham writes, it is the idiotes' ability to pause that allows them to reflect and thoughtfully express political or social concern, Jeanne and Marie's ability to stop is what also enables them to move through the unaccommodating spaces they encounter.

The empowerment of the two women manifests aesthetically as an ability to pause and keep moving. According to Naila Kabeer, empowerment is inextricably linked to agency and choice: 'the expansion in people's ability to make strategic life choices' thanks to a combination of three interrelated dimensions: resources (material, human, and social preconditions), agency (process), and achievements (outcomes), whereby agency is the 'people's capacity to define their own life-choices and to pursue their own goals, even in the face of opposition from others' (1999, 437-438). For Sarah Banet-Weiser, however, there is an urgent need to debunk the harmful opposition between agent and victim, and the association of agency with individual choice, which fail to recognise the institutional sexism that keeps women in their place outside of the public sphere (2019). If the two women apparently lack the material and social resources to achieve their goals and become empowered, Jeanne and Marie are far from being depicted as victims. The persistence of the protagonists to move and fully inhabit space are represented aesthetically in the film as bodies that come in front or in the way of the patriarchy that negatively affects their freedom of movement. As the two women resist sexual assault, throw themselves in front of cars to get a ride, enter uninvited into sheds for a place to sleep, and sit at other people's tables in cafés, their bodies visually interrupt the fixity of the frame and give a physical and tangible shape to wilfulness. While several men in the film perceive Jeanne and Marie as prostitutes, thus reproducing the frequent commodification of women in public places, the gun the women steal becomes an extension of their body, the penis they lack in order to move as freely as men do (see Fig. 2.7). The gesture of Jeanne holding the gun as a penis constitutes a queering of gender, reducing it (and men's domination) to an inanimate object, one that others can possess and control. This wilful gesture debunks the myth of the subject as a fixed set of identities, and the gendered dichotomy opposing agents and victims. Rather than as an individual decision, however, this gesture emerges as an affective experience of collective negative affects. As explained in the previous chapter the gendered dichotomy 


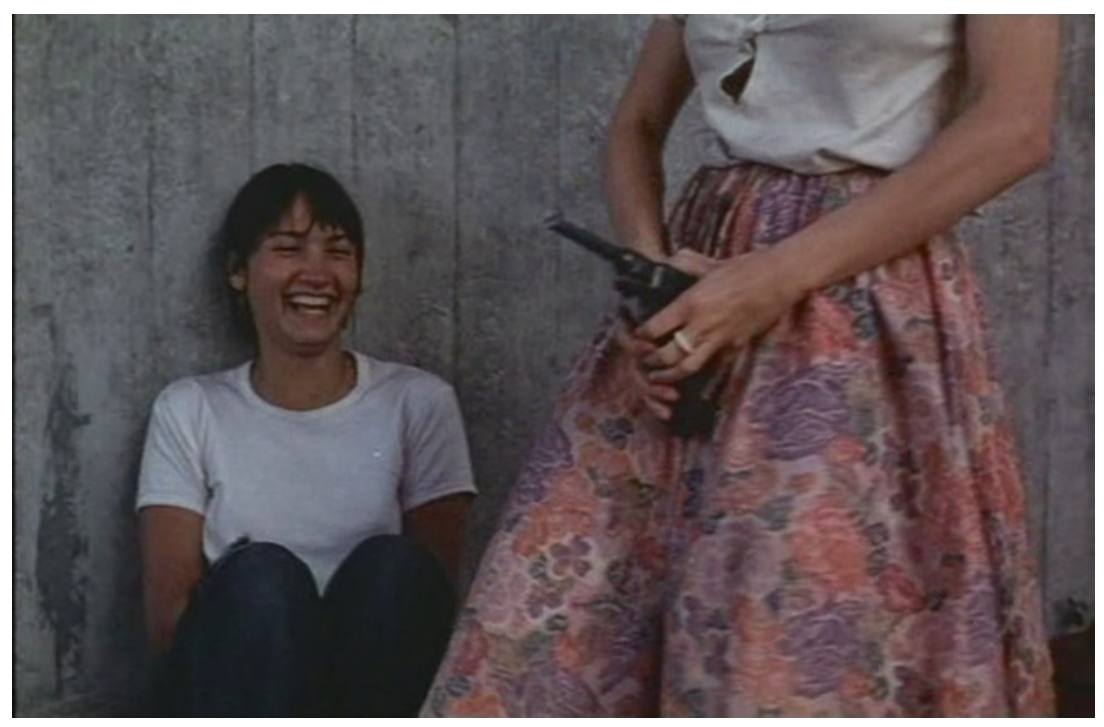

Fig. 2.7 Messidor: A weapon is a penis and vice versa

opposing agents and victims, while also counteracting the gendering of space and myth of the subject as a fixed set of identities.. As explained in the previous chapter, it is the accumulation of being negatively affected in their habitation of 'public' spaces that spurs women's wilful acts. In A Question of Silence (Marleen Gorris 1982), wilfulness is borne out of a casual encounter between women who have suffered from institutionalised forms of sexism and misogyny, which have barred them from inhabiting public spaces as freely as men do. The accentuated sound of the wheels of one woman's shopping trolley and another's pushchair stroller as the two women enter a clothing shop, soon to become a crime scene, brings to the fore the everyday duty they are charged with. The coincidental murder that they commit together in spite of not knowing each other, and the complicit silence of the other women in the shop, points to a societal abuse of women as a collective that eventually results in affirmative resistance. In Messidor, it is also a lack of resources (not having access to their own car) that brings the protagonists together. It is a tiredness of abuse, of not being accommodated-a general accumulation of negative affects - that brings women together and leads to their bonding over wilful acts, which is emphasised in these two films as well as in Butterfly Kiss, Monster, and Frozen River among others. 
In Messidor, it is in fact when the two women decide to thoroughly stop, not as a pause for reflection but to abandon their resistance, that the two characters get caught and are visually cornered at the table of a café. I disagree with Marsha Kinder, who qualifies Messidor as lacking the 'exuberant energy and good humor' of Thelma and Lowise, which is seemingly, for Kinder, necessary to empowerment and feminist politics (1991, 30). While she writes that Ridley Scott's film begins where Tanner's ends, I would say that Thelma and Louise (1991) parallels the narrative of Messidor two decades later. Thelma and Louise's leap into the Grand Canyon has ambiguously come across both as death or as a new movement, a desperate motion out of a patriarchal space pushed by those who represent it. Jeanne and Marie stop because of a similar gendering of space and make their last move by killing someone who they mistakenly suspect called the police and who they thereby perceive as someone who represents the oppressive system. Their leap happens by remaining in place, by wilfully stopping their movement, and calmly inhabiting a space that does not accommodate them. The film closes with a police car driving Jeanne and Marie through an open landscape across the countryside, suggesting an ending that may arguably appear more open than the final scene of Thelma and Louise, if the death of Thelma and Louise suggests a forced end to movement and the possibility of travel. However, both the car driving Jeanne and Marie and the car leaping into the Grand Canyon leave a trace on screen, a trace that aesthetically gives form to the virtual present within the real, the affirmative beyond the negativity of the films' diegeses.

What emerges from this chapter is the importance to look at space and bodies from an analytical lens that does not obscure instances of affirmative aesthetics. As a rewriting of the traditionally men-dominated road movie genre, Messidor portrays men as both enablers of and obstacles to women's journeys. In opposition to the quest of self-discovery of the usual male protagonists, the ability of the women protagonists to pause and reflect allows them to move farther and further. The camera places emphasis on Jeanne and Marie's will not to stop moving, on the long-lasting persistence of their journey, on their slow mobility that leaves a trace. The film and my affirmative approach to the film are critical of the additional obstacles women encounter on the road compared to their male counterparts. While Messidor emphasises how the road movie does not work for women's empowerment and full habitation of space, the film's aesthetic creates glimpses of future possibilities: transformations of the binary schemes of men and women, mobility and stasis, road and home. 


\section{Note}

1. I deliberately use the term 'social' instead of 'public' spaces in order to signal the problem of naming social spaces 'public' when these are not freely available to all.

\section{REFERENCES}

Akin, Fatih. 2004. Gegen Die Wand [Head-On]. DVD. Germany/Turkey: Strand Releasing.

Arnold, Andrea. 2016. American Honey. DVD. UK/USA: Film4.

Banet-Weiser, Sarah. 2019. Rewriting Female Victimbood. Conference Paper Presented at the International Symposium Keeping Up with Empowerment and Popular Misogyny, May 17, Universitat Jaume I, Spain.

Blum-Reid, Sylvie. 2016. Traveling in French Cinema. Hampshire/New York: Palgrave Macmillan.

Bruno, Giuliana. 2002. Atlas of Emotion: Journeys in Art, Architecture, and Film. London/New York: Verso.

Cohan, Steven, and Ina Rae Hark. 1997. The Road Movie Book. London: Routledge.

Corrigan, Timothy. 1992. A Cinema without Walls: Movies and Culture after Vietnam. London: Routledge.

De Lauretis, Teresa. 1984. Alice Doesn't: Feminism, Semiotics, Cinema. Bloomington/Indianapolis: Indiana University Press.

Eyerman, Ron, and Orvar Löfgren. 1995. Romancing the Road: Road Movies and Images of Mobility. Theory, Culture and Society 12 (1): 53-79.

Frederick, Bonnie, and Virginia Hyde. 1993. Introduction. In Women and the Journey: The Female Travel Experience, ed. Bonnie Frederick and Susan H. McLeod, xvii-xxxiii. Washington, DC: Washington University Press.

Fullwood, Natalie. 2015. Cinema, Gender, and Everyday Space: Comedy, Italian Style. New York: Palgrave Macmillan.

Gatlif, Tony. 2006. Transylvania. DVD. France: Mongrel Media.

Gorris, Marleen. 1982. De stilte rond Christine M. [A Question of Silence]. DVD. Netherlands: Sigma Film Productions.

Gott, Michael, and Thibaut Schilt. 2013. Open Roads, Closed Borders: The Contemporary French-Language Road Movie. Bristol: Intellect.

Hunt, Courtney. 2008. Frozen River. DVD. USA: Cohen Media Group.

Ince, Kate. 2017. The Body and the Screen: Female Subjectivities in Contemporary Women's Cinema. London/Oxford: Bloomsbury. 
Ingraham, Chris. 2020. (forthcoming). Gestures of Concern. Durham: Duke University Press.

Jenkins, Patty. 2003. Monster. DVD. USA/Germany: Media 8 Entertainment.

Kabeer, Naila. 1999. Resources, Agency, Achievements: Reflections on the Measurement of Women's Empowerment. Development and Change 30 (3): 435-464.

Kar-Wai, Wong. 2007. My Blueberry Nights. DVD. Hong Kong: Roadshow Entertainment.

Kinder, Marsha. 1991. The Many Faces of Thelma \& Louise: Thelma \& Louise and Messidor as Feminist Road Movies. Film Quarterly 45 (2): 20-31.

Laderman, David. 2002. Driving Visions: Exploring the Road Movie. Austin: University of Texas Press.

Loden, Barbara. 2006 [1970]. Wanda. DVD. USA: Parlour Pictures.

Mazierska, Ewa, and Laura Rascaroli. 2006. Crossing New Europe: Postmodern Travel and the European Road Movie. London/New York: Wallflower Press.

Miller, Claude. 1983. Mortelle randonnée. VHS. France: TFl Films Production.

Mills, Katie. 2006. The Road Story and the Rebel: Moving Through Film, Fiction, and Television. Carbondale: Southern Illinois University Press.

Orgeron, D. 2008. Road Movies: From Muybridge and Melies to Lynch and Kiarostami. New York: Palgrave Macmillan.

Pérez, Jorge. 2011. Cultural Roundabouts: Spanish Film and Novel on the Road. Lewisburg: Bucknell University Press.

Petzold, Christian. 2007. Yella. DVD. Germany: Cinema Guild.

Pratt, Mary-Louise. 2012. On Staying. Conference Paper Presented at the Travel Ideals: Engaging with Spaces of Mobility, July 18, University of Melbourne, Australia.

Ramsay, Lynne. 2003. Morvern Callar. DVD. UK/Canada: Palm Pictures.

Reichardt, Kelly. 2008. Wendy and Lucy. DVD. USA: Madman Entertainment.

Robertson, Pamela. 1997. Home and Away: Friends with Dorothy on the Road in Oz. In The Road Movie Book, ed. Steven Cohan and Ina Rae Hark, 271-286. London: Routledge.

Rollet, Brigitte. 2003. Women Directors and Genre Films in France. In Women Filmmakers: Refocusing, ed. Judith Plessis Jacqueline Levitin and Valérie Raoul, 127-137. UBC Press.

Royer, Michelle. 2011. The Hijacking of a Genre: French Female Film-Makers and the Road Movie. In Parcours De femmes: Twenty years of women in French, Modern French Identities, ed. Maggie Allison and Angela Kershaw, 243-256. Oxford: Peter Lang.

Sanders-Brahms, Helma. 2008 [1980]. Deutschland Bleiche Mutter [Germany, Pale Mother]. DVD. West Germany: Facets Video.

Schanelec, Angela. 2004. Marseille. DVD. Germany: Filmgalerie 451. 
Scott, Ridley. 2002 [1991]. Thelma and Louise. DVD. USA: MGM Home Entertainment.

Tanner, Alain. 1992 [1976]. Jonas qui aura 25 ans en l'an 2000. VHS. Switzerland; France: New Yorker Video.

- 1995 [1979]. Messidor. VHS. Switzerland: Citel Films.

Tarr, Carrie, and Brigitte Rollet. 2001. Cinema and the Second Sex: Women's Filmmaking in France in the 1980s and 1990s. New York: Continuum.

Uteng, Tanu Priya, and Tim Cresswell. 2008. Gendered Mobilities. Farnham: Ashgate Publishing.

Varda, Agnès. 1985. Sans toit ni loi [Vagabond]. VHS. France: Ciné Tamaris.

Wenders, Wim. 1976. Kings of the Road. VHS. West Germany: Wim Wenders Productions.

Wilson, Elizabeth. 1991. The Sphinx in the City: Urban Life, the Control of Disorder, and Women. Berkeley: University of California Press.

Winterbottom, Michael. 1995. Butterfly Kiss. DVD. United Kingdom: First Run Features.

Open Access This chapter is licensed under the terms of the Creative Commons Attribution 4.0 International License (http://creativecommons.org/licenses/ by $/ 4.0 /$ ), which permits use, sharing, adaptation, distribution and reproduction in any medium or format, as long as you give appropriate credit to the original author(s) and the source, provide a link to the Creative Commons licence and indicate if changes were made.

The images or other third party material in this chapter are included in the chapter's Creative Commons licence, unless indicated otherwise in a credit line to the material. If material is not included in the chapter's Creative Commons licence and your intended use is not permitted by statutory regulation or exceeds the permitted use, you will need to obtain permission directly from the copyright holder.

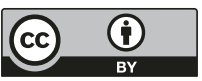

